\section{OBSERVATION OF A CASE OF PURULENT OTITIS MEDIA, CEREBELLAR ABSCESS AND DEATH IN THREE WEEKS.}

Read in the Section of Laryngology and Otology, at the Forty-thir
Annual Meetiug of the American Medical Association, held at DeAunual Meeting of the American Medical Association, held at Detroit, Mich., June, 1892.

BY C. H. BURNETT, M.D., OF PHILADELPHIA, PA.

The patient was a little girl $5 \frac{1}{2}$ years old. She was attacked with acute otitis media January 24,1892 , and allowed by the family physician, a homœopathic one, to suffer a week without paracentesis of the membrane. At the end of that time spontaneous rupture occurred and muco-pus flowed from the meatus. The child, however, drooped and complained of headache, though she was free from earache. Gradually, by the end of the second week, the patient showed well-marked symptoms of cerebral abscess, and at the end of the third week the case was abandoned by the irregular practitioner and other consultants were called in. I recognized the condition of the patient when I was summoned to see her on February 10, 1892.

At my suggestion, Dr. Wm. W. Keen was called in with a view to his trephining for relief of the cerebral abscess. The precise position of the latter could not be located. Dr. Keen first opened the mastoid cavity, finding it filled with cheesy pus. He then made an inch trephine opening, the centre-pin being placed $11 / 4$ inch above and behind the external auditory meatus. Exploration of the anterior and middle fossæ of the skull failed to reveal pus in either fossa. A grooved director passed into the temporo-sphenoidal lobe also failed to discover pus. The child recovered well from the ether, but gradually sank and died eleven hours after the operation. Post-mortem examination thirty-six hours later revealed an abscess in the right hemisphere (side of affected ear), containing 2 fluid ozs. of odorless pus.

Straight instruments have been found preferable to those set at an angle with the handle. The patient should be lifted as high as is safe in the anæsthetic state, which can be effected by having the head and shoulder piece of the operating table hinged. The teeth should be in a good condition before the operation of excision is performed.

In two cases of chronic catarrhal otitis media I have operated on both ears, with fair results, considering the degree of the deafness and sclerosis.

In a case of chronic purulent otitis media, in a boy 12 years old, excision of the swollen and granulating membrana tympani, with the malleus, was followed by cessation of discharge and an improvement in the hearing for isolated words, from 2 feet to 20 feet.

EARLY DIAGNOSES OF MASTOID DISEASE AND OPERATION AS A LIFE SAVING

MEASURE, IN THE PREVENTION OF PY EMIC AND MENINGITIC COMPLICATIONS.

Read in the Section of Laryngology and Otology at the Forty-third Annual Meeting of the American Medical Association, held in Detroit, Mich., June. 1892.

BY D. MILTON GREENE, M.D., OF GRAND RAPIDS, MYCH.

[ABSTRACT.]

Five cases of suppuration in the mastoid cells following acute suppurative otitis media, without external signs of mastoid disease.

No pain referred to mastoid. Acute pain lasting until perforation of membrana tympani.

Temperature in four cases reached 104 or above, and in one only 102 , before operation.

Operation in four cases with recovery. No opera- tion in one, which resulted in perforation, pyæmia and death.

Early diagnosis made in latter case.

Autopsy.

Pain, redness, swelling and odema over mastoid, not essentially signs of suppuration in cells.

Opened lateral sinus in one case with no bad effect.

ABSTRACT AND REMARKS ON A CASE OF THE SO-CALLED BEZOLD VARIETY OF MASTOIDITIS ; MASTOTOMY ; CRANIOTOMY ; DEATH.

AUTOPSY: ABSCESS IN TEMPORAL LOBE AND CEREBELLAR HEMISPHERE; THROMBO-PHLEBITIS ON BOTH SIDES.

Read in the Section of Laryngology and Otology, at the Forty-third Annual Meeting of the American Medical Association, held at Detroit, Mich., June, 1892.

BY HERMAN KNAPP, M.D., OF NEW YORK.

Mr. President:-My paper contains a detailed description of one of the most important and instructive cases of my aural practice. It is, however, too long to be read before this Society. I, therefore, would beg permission to read only a résumé of it, and some general remarks, which I offer for publication in The Journal of the American Medical Association, if acceptable, whereas I intend to publish the case in full in The Archives of Otology (July number, 1892).

If we recapitulate the history of the case, we find a young woman of good constitution, suffering during the course of a year from repeated attacks of acute naso-pharyngeal catarrh, extending into both ears. The left ear recovered. The fourth and later attacks showed implications of the right mastoid with marked meningitic irritation. She was pregnant; during the last months the attacks were more severe. The upper part of the sterno-mastoid become red, swollen, and painful; ten days after her confinement her physician made a deep incision into the swollen head of the muscle, liberating a good deal of pus. The relief being only temporary, I opened the mastoid from base to tip, found pus in the upper part, and kept the wound open by a perforated silver tube. The patient felt relief, but soon had a pleuritic exudation as an intercurrent disease, which disappeared in less than two weeks. Discharged from the hospital as cured she felt well for two weeks, then symptoms of cerebral irritation returned and with varying intensity lasted until her death, three months later. These symptoms were: Persistent headache, nausea, occasional vomiting, vertigo, stupor, impediment of speech, loss of appetite, constipation. The pulse at first varied between 70 and 88 , later sank to 60 per minute, the temperature was between $98.4^{\circ}$ to $101^{\circ}$, never changing rapidly. There were no convulsions, deliria, chills or abnormality of sensation. The ear never gave her any trouble, and there never was any discharge from the ear canal, though the drumhead and adjacent portion of the ear canal was red and bulging. Two months before death a sudden swelling was noticed below the head of the other (left) sterno-mastoid muscle. The eyes, examined with the ophthalmoscope, were found healthy until the last month, when the development of optic neuritis could be distinctly 